\title{
FBXL20-mediated Vps34 ubiquitination as a 53 controlled checkpoint in regulating autophagy and receptor degradation
}

\author{
Juan Xiao, ${ }^{1}$ Tao Zhang, ${ }^{1,3}$ Daichao Xu, ${ }^{1,3}$ Huibing Wang, ${ }^{1,3}$ Yu Cai, ${ }^{1}$ Taijie Jin, ${ }^{1}$ Min Liu, ${ }^{1}$ Mingzhi Jin, ${ }^{2}$ \\ Kejia $\mathrm{Wu}^{1}$ and Junying Yuan ${ }^{1,2}$ \\ ${ }^{1}$ Interdisciplinary Research Center on Biology and Chemistry, Shanghai Institute of Organic Chemistry, Chinese Academy \\ of Sciences, Shanghai 200032, China, ${ }^{2}$ Department of Cell Biology, Harvard Medical School, Boston, Massachusetts 02115, USA
}

Vacuolar protein-sorting 34 (Vps34), the catalytic subunit in the class III PtdIns3 (phosphatidylinositol 3) kinase complexes, mediates the production of PtdIns3P, a key intracellular lipid involved in regulating autophagy and receptor degradation. However, the signal transduction pathways by which extracellular signals regulate Vps34 complexes and the downstream cellular mechanisms are not well understood. Here we show that DNA damageactivated mitotic arrest and CDK activation lead to the phosphorylation of Vps34, which provides a signal to promote its ubiquitination and proteasomal degradation mediated by FBXL20 (an F-box protein) and the associated Skp1 (S-phase kinase-associated protein-1)-Cullin1 complex, leading to inhibition of autophagy and receptor endocytosis. Furthermore, we show that the expression of FBXL20 is regulated by p53-dependent transcription. Our study provides a molecular pathway by which DNA damage regulates Vps34 complexes and its downstream mechanisms, including autophagy and receptor endocytosis, through SCF (Skp1-Cul1-F-box)-mediated ubiquitination and degradation. Since the expression of FBXL20 is regulated by p53-dependent transcription, the control of Vps34 ubiquitination and proteasomal degradation by FBXL20 and the associated SCF complex expression provides a novel checkpoint for $\mathrm{p} 53$ to regulate autophagy and receptor degradation in DNA damage response.

[Keywords: Vps34; autophagy; p53]

Supplemental material is available for this article.

Received September 10, 2014; revised version accepted December 3, 2014.

Vacuolar protein-sorting 34 (Vps34), the primordial member of the class III PtdIns3 (phosphatidylinositol 3) kinase family, is the catalytic subunit in the Vps34 complexes that mediate the production of PtdIns3P, a key intracellular lipid involved in regulating multiple intracellular vesicular trafficking processes such as autophagy, endocytosis, and receptor degradation (Backer 2008). Vps34 was first isolated in a screen for genes involved in regulating vesicular trafficking of the yeast Saccharomyces cerevisiae (Herman and Emr 1990). PtdIns3P, the product of Vps34 complexes, functions by interacting with proteins containing the FYVE or PX domains to nucleate the formation of various protein complexes on the intracellular membranes-such as endosomes, phagosomes, and autophagosomes-to regulate vesicular trafficking and protein turnover (Backer 2008). Dynamic regulation of Vps34 complexes may provide an important regulatory mechanism to control multiple vesicular trafficking pathways, which in turn regulate intracellular signaling.

\footnotetext{
${ }^{3}$ These authors contributed equally to this work. Corresponding author: jyuan@hms.harvard.edu

Article is online at http://www.genesdev.org/cgi/doi/10.1101/gad.252528.114.
}

For example, endocytosis is known to regulate the strength and duration of intracellular signaling by controlling the internalization of the ligand-receptor complex, which may lead to its degradation (Hupalowska and Miaczynska 2012). Thus, understanding the molecular mechanisms that control the levels of Vps34 is important for us to appreciate how intracellular vesicular processes are regulated in response to external cellular stimuli under physiological and pathological conditions. In this regard, CDK1 was shown to phosphorylate the T159 residue of Vps34 during mitosis to negatively regulate Vps34 (Furuya et al. 2010); however, the significance and mechanism of Vps34 phosphorylation in the DNA damage response were not clear.

Autophagy is an important catabolic process mediating the turnover of intracellular constituents in a lysosomedependent manner (Levine and Kroemer 2008; Mizushima

(C) 2015 Xiao et al. This article is distributed exclusively by Cold Spring Harbor Laboratory Press for the first six months after the full-issue publication date (see http://genesdev.cshlp.org/site/misc/terms.xhtml). After six months, it is available under a Creative Commons License (Attribution-NonCommercial 4.0 International), as described at http:// creativecommons.org/licenses/by-nc/4.0/. 
2011). In metazoans, autophagy functions as an important intracellular catabolic mechanism involved in regulating cellular homeostasis during development and adult life by mediating the turnover of malfunctioning, aged, or damaged proteins and organelles. In mammalian cells, Vps34, in complex with its regulatory subunits such as Beclin 1 and $\operatorname{Atg} 14 \mathrm{~L}$, is an important regulator of autophagy (Simonsen and Tooze 2009; Funderburk et al. 2010). Although DNA damage has been shown to lead to suppression of autophagy in a p53-dependent manner (Cheng et al. 2013), the mechanism by which the transcriptional regulation of p53 leads to suppression of autophagy upon DNA damage response is not clear.

F-box family proteins (FBPs), which are the substrate recognition components of the Skp1 (S-phase kinaseassociated protein-1)-Cul1-F-box protein (SCF) ubiquitin ligase complexes, control the intracellular signaling by regulating the abundance of critical mediators of cellular functions through ubiquitination and proteasomal degradation (Cardozo and Pagano 2004). In the SCF complex, the cullin subunit Cull functions as a molecular scaffold that simultaneously interacts with the adaptor subunit Skpl and a RING finger protein (Rbxl [also known as Roc1] or Roc2), whereas Skp1 binds to one of many FBPs, which interacts with specific substrates through a protein-protein interaction domain. FBPs bind substrates in response to various stimuli and often with short, defined motifs involved in mediating degradation, known as degrons (Skaar et al. 2013). In this study, we examined the role of one of the FBPs, FBXL20 (also known as SCRAPPER) (Yao et al. 2007), in regulating the ubiquitination and proteasomal degradation of Vps34 to control intracellular vesicular processes such as autophagy and receptor degradation. FBXL20 is a 438 -amino-acid protein that contains an F-box, leucine-rich repeats (LRRs), and a C-terminal CAAX domain, a site of prenylation for membrane anchorage. FBXL20 has been shown to form an SCF complex with Skp1 and Cullin1 that is involved in regulating neuronal synaptic vesicle release (Yao et al. 2007). Here we show that FBXL20 regulates the abundance of Vps34 through SCF complex-mediated ubiquitination and proteasomal degradation in a phosphorylation-dependent manner. Furthermore, we show that the expression of FBXL20 is activated by p53-dependent transcription in response to DNA damage. Our study provides a molecular mechanism by which p53 controls autophagy and receptor degradation through ubiquitination and proteasomal degradation of Vps34.

\section{Results}

FBXL20 regulates the levels of Vps34 and autophagy

FBXL20 was identified in a genome-wide siRNA screen as a gene when its expression was knocked down, leading to the induction of autophagy flux and increases in the levels of PtdIns3P (Supplemental Fig. S1A; Lipinski et al. 2010). Since the class III PtdIns3 kinase is involved in mediating the production of PtdIns3P, we hypothesized that FBXL20 may affect the levels or activity of Vps34 complexes. To test this hypothesis, we characterized the effects of FBXL20 knockdown on the levels of proteins in the Vps34 complexes, including Vps34, Beclin1, Vps15, and Atg14. Interestingly, we found that the levels of Vps34 selectively increased when FBXL20 was knocked down in H4-GFP-LC3, HeLa, and U2OS cells, with a corresponding increase in the ratio of LC3II to tubulin; on the other hand, the levels of other proteins in the Vps34 complexesincluding Vps15, Atg14L, and Beclin1-were not affected (Fig. 1A,B; Supplemental Fig. S1B). Consistently, a specific increase in the levels of Vps34 protein was also observed in FBXL20 stable knockdown cells (Fig. 1C). Furthermore, the effect of knockdown FBXL20 on Vps34 and autophagy can be suppressed by expression of FBXL20 (Fig. 1D).

To characterize a possible regulatory relationship of FBXL20 with Vps34, we transfected an expression vector of FBXL20 into H4, HeLa, or 293T cells. Consistent with regulation of Vps34 by FBXL20, overexpression of FBXL20 or CUL1/SKP1 in H4 (Fig. 1E) and HeLa cells (Supplemental Fig. S2A) down-regulated the levels of Vps34 protein without affecting the levels of Atg12-Atg5 conjugate. Consistent with an increased degradation of Vps34, the reduction of Vps34 by overexpression of FBXL20 in HeLa cells (Fig. 1F), H4 cells (Supplemental Fig. S2B), and 293T cells (Supplemental Fig. S2C) can be rescued by treatment with MG132, an inhibitor of proteasomal degradation. In addition, MG132 treatment in HeLa cells overexpressing FBXL20 partially restored the levels of LC3II while having no effect on the levels of Beclin 1 and Atg14 (Fig. 1F). Taken together, these results suggest that FBXL20-SKP1-CUL1 regulates the levels of Vps34 and autophagy through a proteasomal pathway.

\section{Reciprocal regulation of Vps34 and FBXL20 by DNA damage response}

FBXL20 was identified as one of the genes transcriptionally regulated by p53 upon DNA damage in a global p53regulated transcriptional network analysis (Kenzelmann Broz et al. 2013). To examine the potential impact of DNA damage on the levels of Vps34 and FBXL20, we first examined the levels of Vps34 and FBXL20 mRNA after treatment with camptothecin $(\mathrm{CPT})$, a cytotoxic quinoline alkaloid that can inhibit the DNA enzyme topoisomerase I and activate DNA damage response. We found that the levels of FBXL20 mRNA increased after CPT treatment, while the levels of Vps34 mRNA in HeLa cells were stable (Fig. 2A). Consistent with an induction of FBXL20 expression, treatment with CPT together with cycloheximide reduced the levels of FBXL20 proteins compared with that of CPT alone (Supplemental Fig. S3A). Consistently, knockdown of p53 eliminated the effect of CPT treatment on the induction of FBXL20 mRNA and protein (Fig. 2B,C). Thus, p53 is likely to play a critical role in the up-regulation of FBXL20 in response to CPT treatment.

To further test the role of p53 in regulating the expression of FBXL20, we treated HCT116 wild-type and HCT116 p53 ${ }^{-1-}$ cells with CPT. We found that CPT treatment in HCT116 wild-type cells induced the expression of FBXL20 in a dose- and time-dependent manner (Fig. 2D,E). On the other hand, the expression of FBXL20 in HCT116 p53-/- 
Xiao et al.
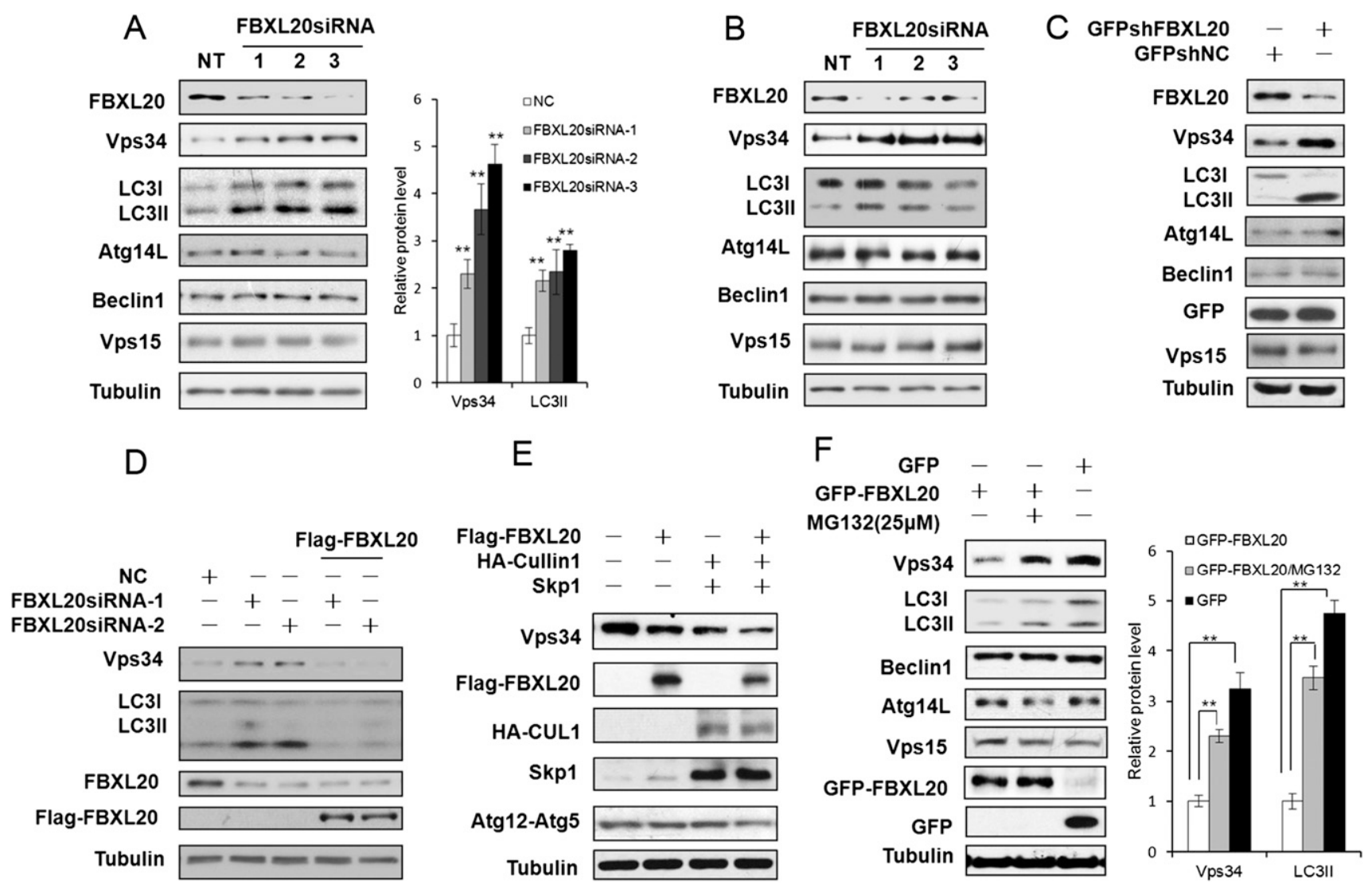

Figure 1. FBXL20 promotes UPS-mediated degradation of Vps34. $(A, B)$ H4-LC3-GFP cells $(A)$ and HeLa cells $(B)$ were transfected with control siRNA or siRNA targeting FBXL20 and cultured for $72 \mathrm{~h}$. The total cell lysates were analyzed by Western blotting with the indicated antibodies. $(C)$ HeLa cells stably expressing control shRNA or GFPshRNA FBXL20 were analyzed by Western blotting with the indicated antibodies. $(D)$ Control siRNA or siRNA targeting the FBXL20 3' untranslated region (UTR) were transfected into HeLa cells and cultured for $24 \mathrm{~h}$ before the cells were transfected again with FBXL20-expressing vector and incubated for another $48 \mathrm{~h}$. The cell lysates were analyzed by Western blotting with the indicated antibodies. $(E)$ H4 cells were transfected with expression vectors of Flag-FBXL20 and HA-CUL1/Skp1 and cultured for $36 \mathrm{~h}$. The cell lysates were analyzed by Western blotting with the indicated antibodies. (F) HeLa cells were transfected with GFP control vector or GFP-FBXL20 expression vector and cultured for $44 \mathrm{~h}$ followed by treatment with $25 \mu \mathrm{M}$ MG132 for $4 \mathrm{~h}$. The cells were harvested, and the lysates were analyzed by Western blotting with the indicated antibodies. Tubulin was the loading control for all blots. The graphs were quantified using Image J as means \pm SD of three independent sets of experiments. $\left(^{\star \star}\right) P<0.01$.

cells did not respond to CPT treatment. Consistent with the antagonistic regulatory relationship of FBXL20 and Vps34, CPT treatment in HeLa cells led to increases in the levels of FBXL20 and showed a corresponding negative impact on the levels of Vps34 in a time- and dose-dependent manner (Fig. 2F,G).

Corresponding to a reduction in the levels of Vps34 induced by CPT, the levels of LC3II decreased when cells were treated with CPT (Fig. 2H; Fig. 6B [below]), suggesting that autophagy is inhibited upon CPT treatment. Consistent with this possibility, CPT treatment reduced the ratios of LC3II to Tubulin in the presence of CQ (Supplemental Fig. S3B,C), suggesting a blockage in autophagic flux by CPT. The reciprocal relationship of FBXL20 with Vps34 and LC3II suggests that Vps34 and autophagy may be negatively regulated by FBXL20 upon CPT treatment.

Treatment of HCT116 cells (wild-type p53) with CPT led to progressive increases in the levels of FBXL20 and a corresponding reduction in Vps34 (Fig. 2I). On the other hand, the levels of FBXL20 and Vps34 in HCT116 p53 cells change only slightly under CPT treatment. Consistent with the levels of Vps34, the levels of autophagy, as measured by the ratio of LC3II to tubulin, in HCT116 p53 $3^{-/-}$cells remained relatively stable.

Similar to CPT treatment, treatment with cisplatin, another DNA-damaging agent and chemotherapeutic agent, also led to increases in the levels of FBXL20 as well as a corresponding reduction in the levels of Vps34 and autophagy (Supplemental Fig. S4A,B). In addition, we found that while treatment with multiple inducers of DNA damage agents, such as cisplatin and doxorubincin, led to a transient increase in autophagy, as marked by the ratio of LC3II to Tubulin, long-term treatment with DNA damage agents all led to reduction of autophagy in the absence of cell death (Fig. 2I; Supplemental Fig. S4C-F).

We tested the possible effect of apoptosis on the induction of FBXL20. Since CPT is a well-established inducer of 
A
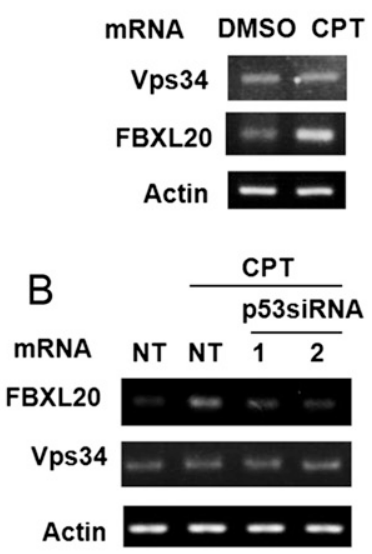

C

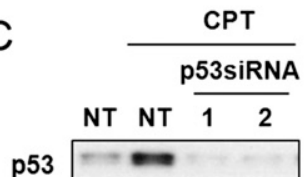

FBXL20 $\ldots \ldots$

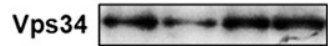

LC3III $=-\overline{-}$

Tubulin

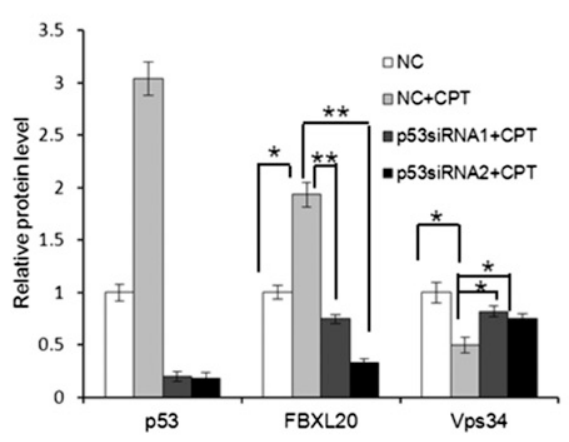

D

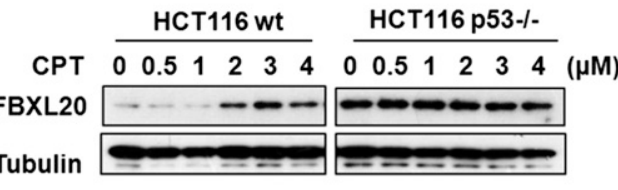

$\mathrm{E}$
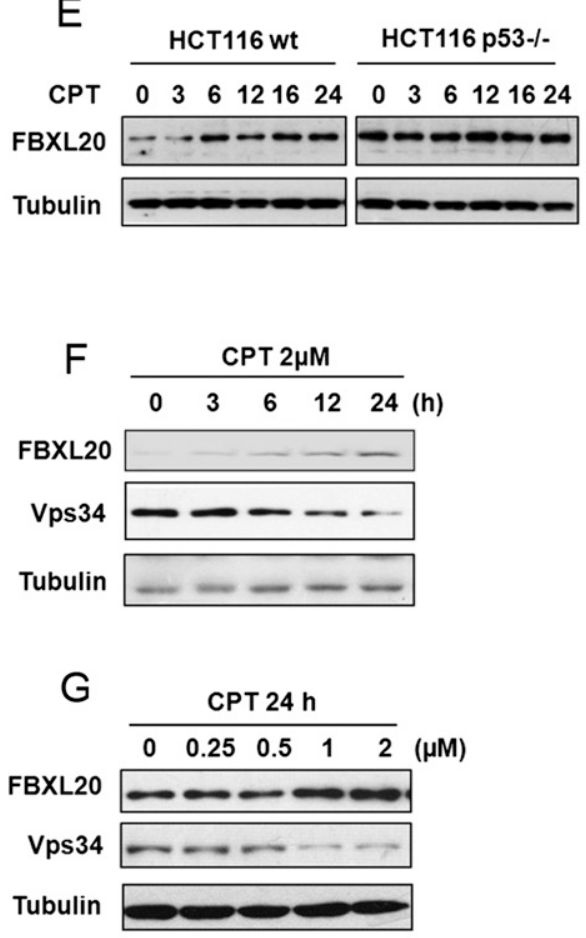

$\mathrm{H}$

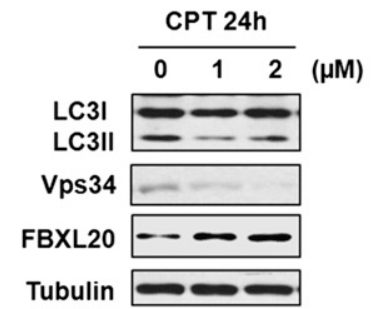

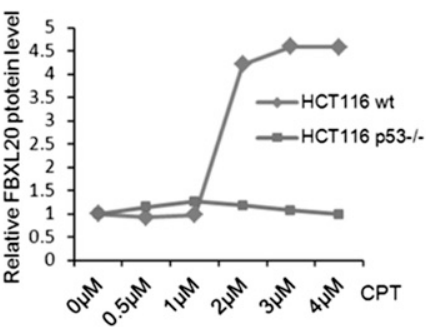
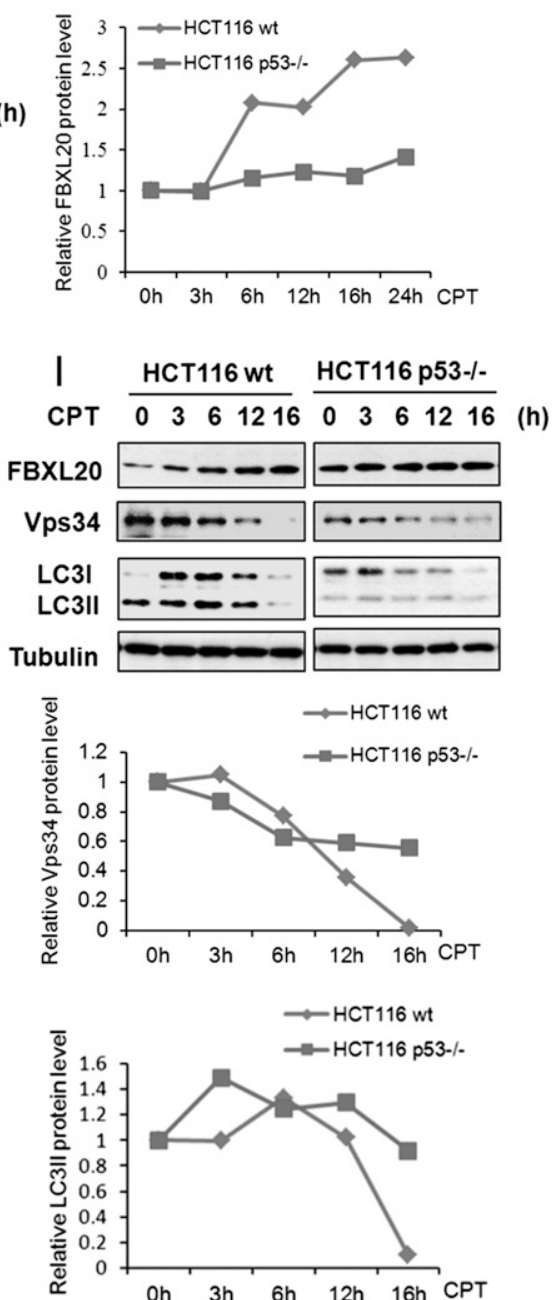

Figure 2. Reciprocal regulation of FBXL20 and Vps34 upon the activation of DNA damage response in a p53-dependent manner. $(A)$ mRNA from HeLa cells treated with $2 \mu \mathrm{M}$ CPT for $24 \mathrm{~h}$ was extracted and analyzed by RT-PCR using primers for the indicated genes. $(B, C)$ HeLa cells were transfected with control siRNA or siRNA targeting p53 and cultured for $48 \mathrm{~h}$ and then treated with $2 \mu \mathrm{M}$ CPT for another $24 \mathrm{~h}$. The mRNA $(B)$ or lysates $(C)$ were prepared and analyzed by RT-PCR using the indicated primers $(B)$ or Western blotting with the indicated antibodies $(C)$. The graphs were quantified using ImageJ as means \pm SD of three independent sets of experiments. $\left({ }^{*}\right)$ $P<0.05 ;\left(^{\star \star}\right) P<0.01$. $(D, E)$ HCT116 wild-type $(\mathrm{wt})$ and HCT116 p53 ${ }^{-/-}$cells were treated with the indicated concentrations of CPT for $24 \mathrm{~h}(D)$ or $2 \mu \mathrm{M}$ CPT for the indicated durations $(E)$, and then the cell lysates were prepared and analyzed by Western blotting with anti-FBXL20 and anti-Tubulin. The results were quantified using ImageJ from two independent experiments. $(F-H)$ HeLa cells were treated with $2 \mu \mathrm{M}$ CPT for the indicated durations or the indicated concentrations of CPT for $24 \mathrm{~h}$. $(G, H)$ Next, the cell lysates were analyzed by Western blotting with the indicated antibodies. (I) HCT116 wild-type and HCT116 p53 ${ }^{-1-}$ cells were treated with $2 \mu M$ CPT for the indicated durations, and then the cell lysates were analyzed by Western blotting with the indicated antibodies. Tubulin was the loading control for all blots.

apoptosis, we tested whether the addition of a caspase inhibitor, zVAD.fmk, might affect the induction of FBXL20. We found that inhibition of caspase activation by zVAD. fmk had no effect on the induction of FBXL20 or reduction of Vps34 (Supplemental Fig. S4C). Furthermore, treatment with staurosporine, an effective inducer of apoptosis, had no effect on the levels of FBXL20 or Vps34 (Supplemental Fig. S4C). 
Xiao et al.

Taken together, our results suggest that p53-mediated transcriptional induction of FBXL20 provides an important control for DNA damage-mediated reduction of Vps34 and autophagy.

\section{Regulation of Vps34 and FBXL20 interaction by DNA damage response}

Since FBXL20 is known to function as an adaptor for CUL1-SKP1-mediated ubiquitination and proteasomal degradation by binding to its substrate, we investigated the possibility that FBXL20 might be able to bind toVps34. We transfected the expression vectors of Vps34 and FBXL20 into $293 \mathrm{~T}$ cells, and the interaction of Vps34 and FBXL20 was examined by immunoprecipitation. We found that while the interaction of Vps34 and FBXL20 was detectable under normal conditions, such an interaction was dramatically enhanced in the presence of proteasomal inhibitor MG132 in 293T cells (Fig. 3A) and U2OS cells (Supplemental Fig. S5A).

We next characterized the domain of Vps34 that interacts with FBXL20. We transfected expression vectors of Flag-tagged Vps34 C2, ACC, and kinase domain into $293 \mathrm{~T}$ cells, and the interactions of the indicated domains of Vps34 with FBXL20 were analyzed by immunoprecipitation (Fig. 3B). The result demonstrates that the $\mathrm{C} 2$ domain of Vps34, the region involved in mediating the interaction of Vps34 and Beclin1 (Furuya et al. 2005; Liang et al. 2006), is important for the interaction between Vps34 and FBXL20. In addition, we also constructed truncation

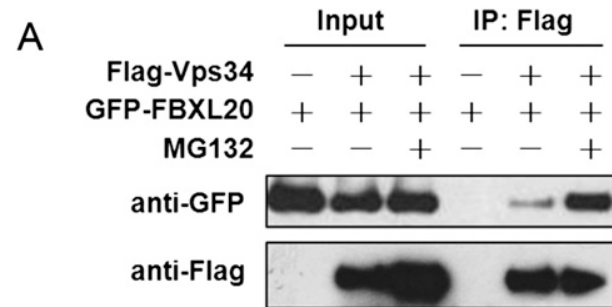

B
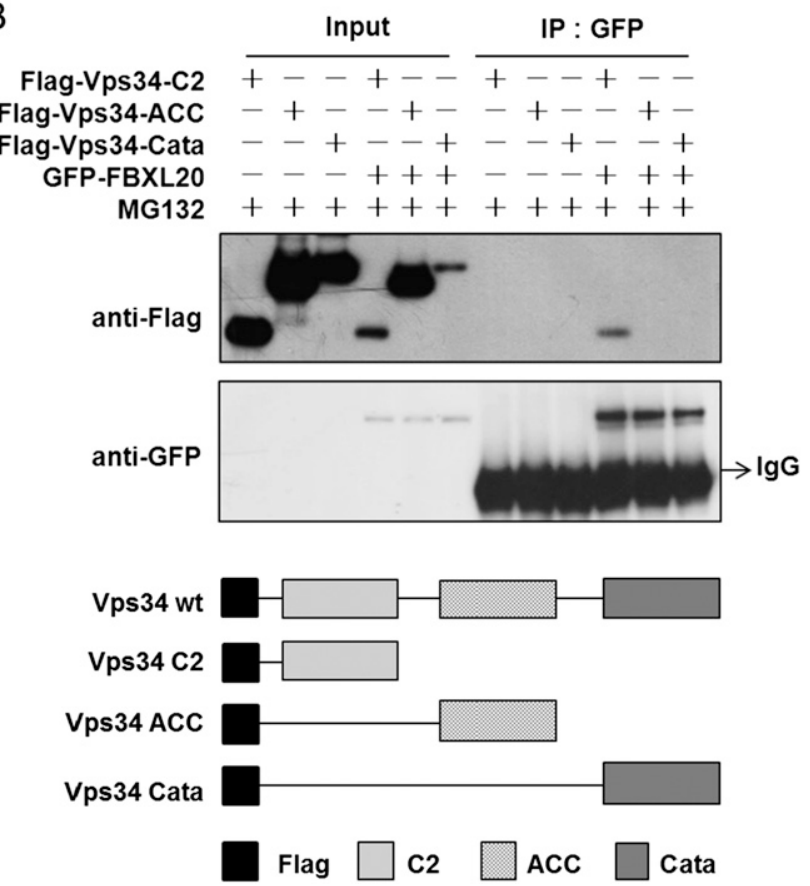

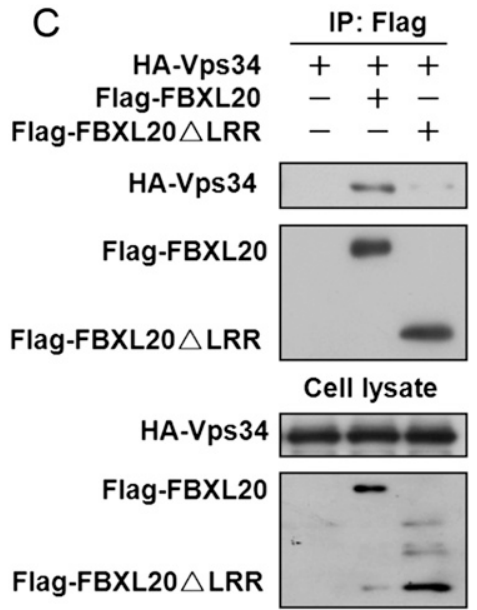

D

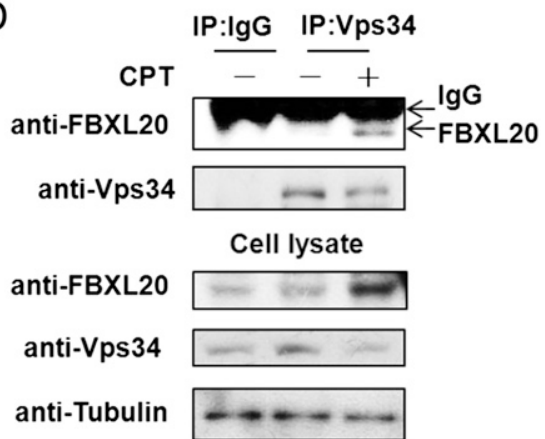

Figure 3. Regulation of the Vps34 and FBXL20 interaction by DNA damage response. $(A, B) 293 \mathrm{~T}$ cells were transfected with expression vectors of Flag-Vps34 and GFP-FBXL20 (A) or GFP-FBXL20, Flag-Vps34-C2, Flag-Vps34-ACC, and Flag-Vps34 kinase domain only (Cata) $(B)$; cultured for $48 \mathrm{~h}$; and then treated with $25 \mu \mathrm{M} \mathrm{MG132}$ for $4 \mathrm{~h}$ in the indicated samples. The cell lysates were analyzed by immunoprecipitation using anti-Flag $(A)$ or anti-GFP $(B)$. A schematic diagram of the truncation constructs is shown below. The immunocomplexes were analyzed by Western blotting using the indicated antibodies. $(C)$ The expression vectors of Flag-tagged wildtype and mutant FBXL20 or HA-Vps34 were transfected into $293 \mathrm{~T}$ cells and cultured for $24 \mathrm{~h}$. The cells were then harvested and lysed in NP-40 buffer. The lysates were immunoprecipitated with anti-Flag antibody, and the immunocomplexes were analyzed by Western blotting using anti-HA antibody. (D) HeLa cells were treated with or without CPT for $24 \mathrm{~h}$, and the cell lysates were analyzed by immunoprecipitation with anti-Vps34 or anti-control IgG. The immunocomplexes were analyzed by Western blotting with the indicated antibodies. 
mutants of FBXL20 and tested their binding with Vps34. We found that the deletion of the C-terminal LRR of FBXL20 eliminated its binding with Vps34 (Fig. 3C); thus, the LRR domain of FBXL20 might be involved in binding with Vps34. Consistently, only the expression of fulllength FBXL20 can modulate the levels of Vps34 (Supplemental Fig. S5C).

Since Vps34 is down-regulated upon DNA damage response induced by $\mathrm{CPT}$, we hypothesize that the interaction of Vps34 with FBXL20 is also enhanced under the same condition. Interestingly, we found that the interaction of the endogenous FBXL20 and Vps34 was detectable upon CPT treatment, which led to an elevated expression of FBXL20 (Fig. 3D). Thus, we conclude that the interaction of FBXL20 with Vps34 is enhanced by DNA damage response.

The CUL1-SKP1-FBXL20 complex mediates the ubiquitination of Vps34

Consistent with the involvement of proteasomal degradation, the down-regulation of Vps34 by CPT treatment in HeLa cells (Fig. 4A) and 293T cells (Supplemental Fig. S5D) was blocked by the proteasome inhibitor MG132. Since FBXL20 functions as an adaptor in the SCF complex (Yao et al. 2007), we hypothesized that the degradation of Vps34 upon CPT treatment is mediated by FBXL20. To directly test this possibility, we knocked down the expression of FBXL20 by siRNA and then treated it with CPT. We found that the reduction in the levels of Vps34 induced by CPT was rescued after the loss of FBXL20 expression (Fig. 4B).

We further validated this result using shRNA-mediated knockdown and coexpression with Flag-Vps34. CPT treatment also led to the down-regulation of overexpressed Vps34 (Fig. 4C). Compared with that of control shRNA transfected cells, knockdown of FBXL20 by shFBXL20 also significantly inhibited the reduction in the levels of Vps34 induced by CPT. Because the F-box domain is known to be important for binding to substrates (Carrano et al. 1999), to further characterize the role of FBXL20, we expressed FBXL20 Fbox, a truncated FBXL20 protein that can bind to its substrate but not the SKP1/CUL1 complex (Fig. 4D) and thus can act as a dominant negative to protect Vps34 from degradation mediated by FBXL20. Interestingly, we found that in cells coexpressing Flag-FBXL20 $\Delta$ Fbox treated with CPT, the degradation of endogenous as well as exogenous Vps34 induced by CPT treatment was significantly protected (Fig. 4E,F). Taken together, these results suggest that FBXL20 is critically important for mediating the down-regulation of Vps34 induced by CPT.

To directly examine the possibility that FBXL20 mediates the ubiquitination of Vps34, we transfected expression vectors for His-tagged ubiquitin, Flag-tagged FBXL20, and HA-tagged Vps34. The ubiquitination of Vps34 was examined by His-ubiquitin pulled down with Ni-NTA agarose beads followed by Western blotting with antiVps34 antibody. The ubiquitination of exogenousVps34 can be clearly observed in cells transfected with FlagFBXL20 compared with control (Fig. 5A). To examine whether overexpression of FBXL20 can ubiquitinate endogenous Vps34, we transfected the expression vectors of Flag-FBXL20 and His-ubiquitin into 293T cells, and ubiquitinated proteins were pulled down with Ni-NTA agarose beads followed by Western blotting using anti-Vps34. We found that the ubiquitination of Vps34 was enhanced by the expression of FBXL20 (Fig. 5B).

To examine whether ubiquitination of endogenous Vps34 is regulated by DNA damage response, we transfected 293T cells with an expression vector of Flag-tagged ubiquitin and then treated cells with CPT. The ubiquitination of endogenous Vps34 was examined by immunoprecipitation and Western blotting with anti-Flag. Consistently, the ubiquitination of endogenous Vps34 was increased in cells stimulated by CPT (Fig. 5C). To examine the role of FBXL20 in Vps34 ubiquitination, we treated HeLa cells with control or knockdown of FBXL20 by expressing an shRNA vector of FBXL20 with CPT. Ubiquitination of Vps34 was examined again using immunoprecipitation and Western blotting with anti-Flag. Interestingly, the ubiquitination of Vps34 was significantly inhibited in HeLa cells with knockdown of FBXL20 (Fig. 5D).

To characterize the ubiquitination of Vps34 in vitro, we purified Myc-Cullin1, Flag-FBXL20, SKP1, and Flag-Vps34 proteins individually from $293 \mathrm{~T}$ cells transfected with respective expression vectors. The eluted proteins were incubated in an in vitro ubiquitination reaction that includes recombinant E1 and E2-Ubc5c. As shown in Figure 5E, the ubiquitination of Vps34 can be observed in the presence of CUL1, SKP1, and FBXL20. Taken together, we conclude that the CUL1-SKP1-FBXL20 complex mediates the ubiquitination of Vps34.

UPS-mediated degradation of Vps34 upon CPT treatment depends on the phosphorylation of T159 in Vps34

Since the recognition of substrates by SCF complexes is facilitated by their phosphorylation (Skaar et al. 2013), we hypothesize that the SCF complex-mediated degradation of Vps34 induced by CPT is also regulated by phosphorylation. CDK1 has been shown to phosphorylate Vps34 T159 during mitosis (Furuya et al. 2010). Treatment with $\mathrm{CPT}$ led to an increase in the levels of cyclin B1 (consistent with mitotic arrest induced by a DNA damage agent) as well as a corresponding reduction in the levels of Vps34 (Fig. 6A). Since the accumulation of cyclin B1 induces the activation of CDK1, we tested the phosphorylation of T159 in Vps34 upon CPT treatment using a phosphor-specific antibody (Furuya et al. 2010). Indeed, CPT treatment induced phosphorylation of T159 with a corresponding reduction of the total levels of Vps34 and increased FBXL20 (Fig. 6B).

To examine the functional importance of CDK-mediated Vps34 phosphorylation in its degradation, we treated cells with CPT and roscovitine, an inhibitor of CDKs. Consistent with an important role of CDK-mediated phosphorylation of Vps34 in its degradation, we found that roscovitine significantly rescued the reduction of transfected and endogenous Vps34 upon CPT treatment without influencing the induction of FBXL20 (Fig. 6C,D). 

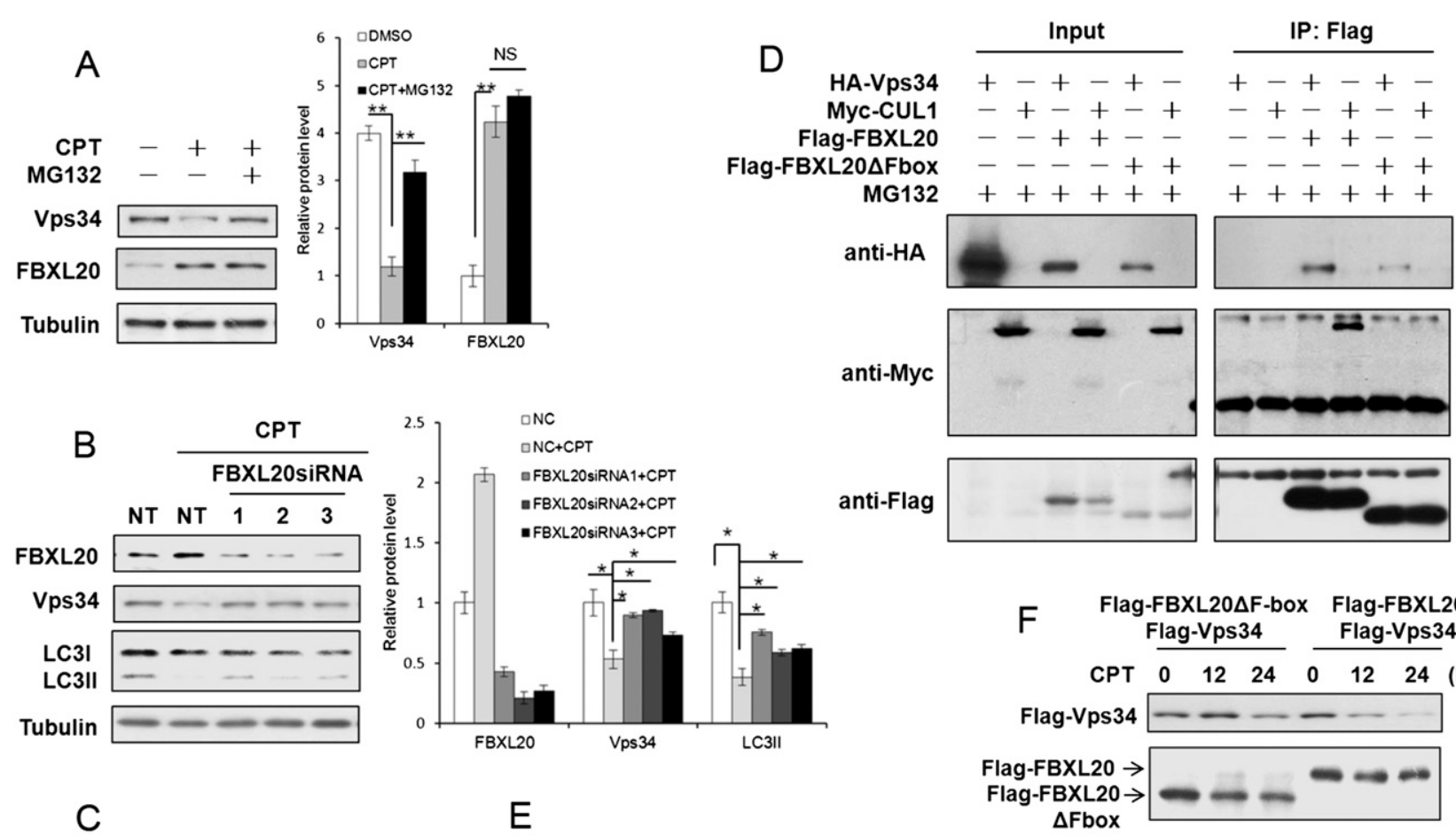

C

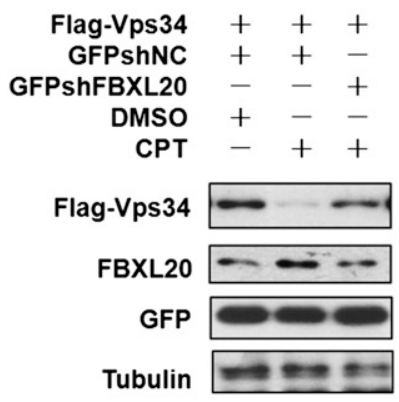

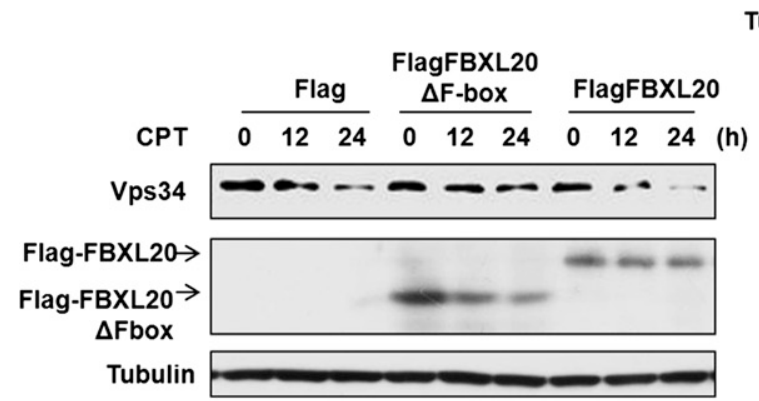
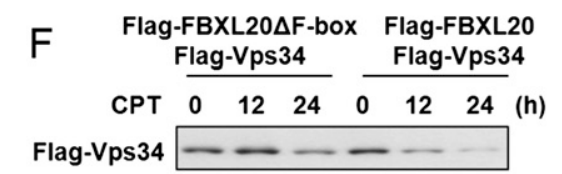

Flag-FBXL20 $\rightarrow$ Flag-FBXL20 $\rightarrow=\infty$ $\Delta$ Fbox Tubulin

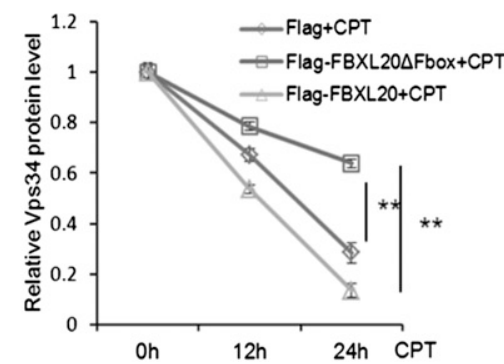

Figure 4. FBXL20-dependent UPS (ubiquitin proteasome system)-mediated degradation of Vps34 upon DNA damage. (A) HeLa cells were treated with $2 \mu \mathrm{M}$ CPT for $24 \mathrm{~h}$ and then with $10 \mu \mathrm{M}$ MG132 for an additional $2 \mathrm{~h}$. The cell lysates were analyzed by Western blotting with the indicated antibodies. The graphs were quantified using ImageJ as means \pm SD of three independent sets of experiments. $\left.{ }^{\star \star}\right) P<0.01$. (B) HeLa cells were transfected with control nontargeting siRNA (NT) or siRNA targeting FBXL20, cultured for $48 \mathrm{~h}$, and then treated with vehicle $(\mathrm{V})$ or $2 \mu \mathrm{M} \mathrm{CPT}$ for $24 \mathrm{~h}$. The cell lysates were analyzed by Western blotting with the indicated antibodies. The graphs were quantified using ImageJ as means \pm SD of three independent sets of experiments. $\left({ }^{\star}\right) P<$ 0.05. (C) Flag-Vps34 expression vector together with either control GFPshRNA vector or GFPshRNA vector targeting FBXL20 was transfected into $293 \mathrm{~T}$ cells, cultured for $48 \mathrm{~h}$, and then incubated with $2 \mu \mathrm{M}$ CPT for an additional $24 \mathrm{~h}$. The cell lysates were analyzed by Western blotting with the indicated antibodies. Anti-GFP was used as a control for the expression levels of shRNA in transfected cells. $(D)$ The expression vectors for HA-Vps34, Myc-CUL1, Flag-FBXL20, and Flag-FBXL20 $\Delta$ Fbox were transfected into $293 \mathrm{~T}$ cells as indicated for $44 \mathrm{~h}$, and then $10 \mu \mathrm{M}$ MG132 was added for an additional $4 \mathrm{~h}$. Next, the cell lysates were analyzed by immunoprecipitation with ant-Flag antibody. The immunocomplexes were analyzed by Western blotting with the indicated antibodies.

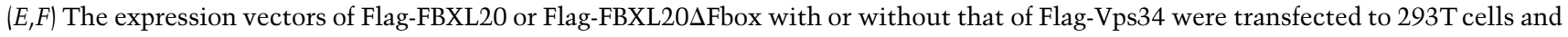
cultured for $48 \mathrm{~h}$, and then $2 \mu \mathrm{M}$ CPT was added for the indicated durations before cell lysis. The cell lysates were analyzed by Western blotting using the indicated antibodies. The graphs were quantified using ImageJ as means \pm SD of three independent sets of experiments. $\left(^{\star \star}\right) P<0.01$.

Furthermore, the increased levels of Vps34 ubiquitination induced by CPT treatment were also inhibited by roscovitine (Fig. 6E). Taken together, we conclude that the degradation of Vps34 activated by DNA damage depends on the phosphorylation of Vps34.

Since we found that the $\mathrm{C} 2$ domain is important for mediating the interaction of Vps34 and FBXL20, we tested the functional role of T159, which is located in the C2 domain, in the interaction with FBXL20. We found that even though it was expressed at levels lower than that of wild type and the T159A mutant, the Vps34T159E mutant interacted much more avidly with FBXL20 than wild type or the T159A mutant did (Fig. 6F; Supplemental Fig. S6A). Surprisingly, the interaction between the Vps34T159A 

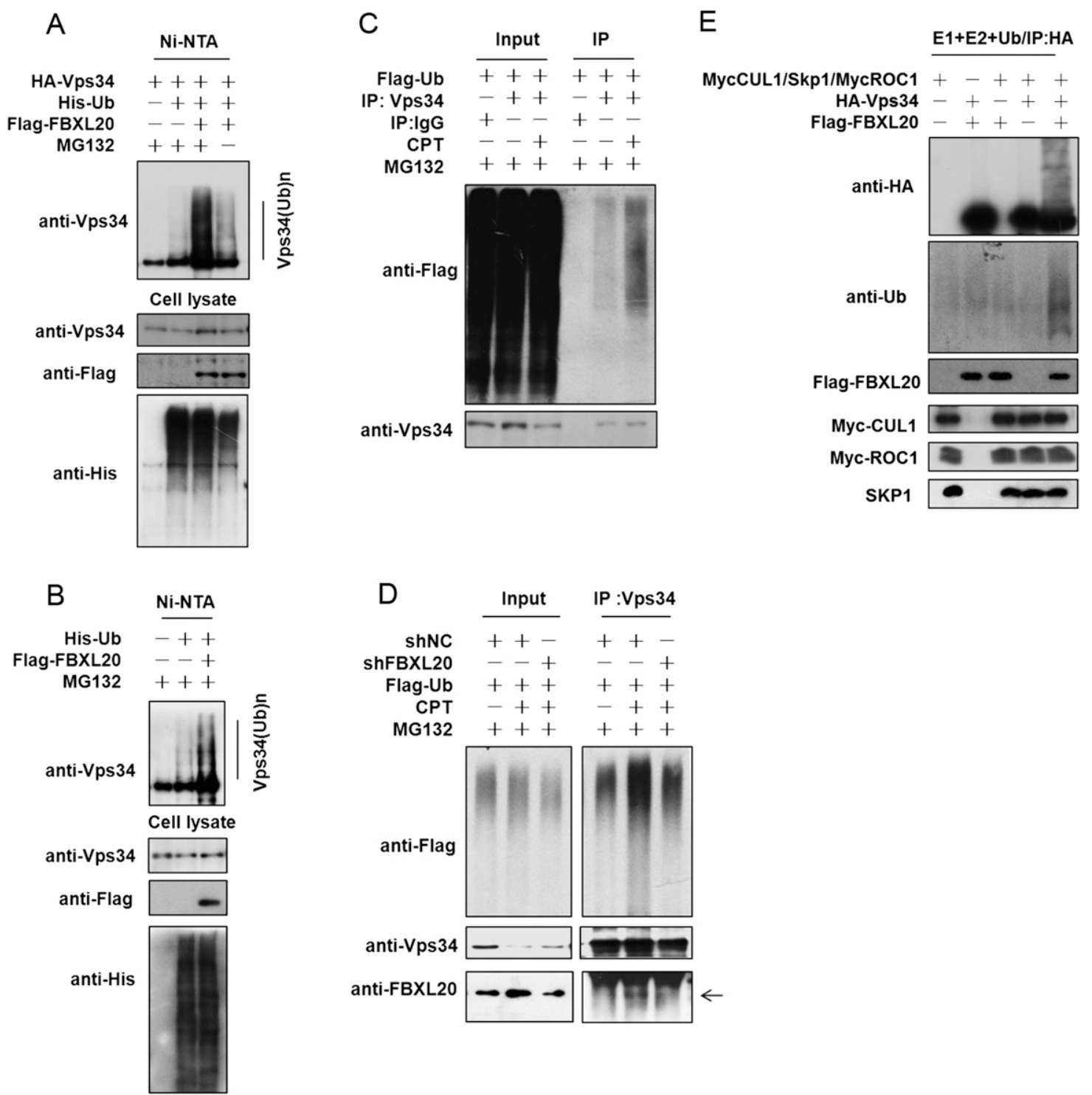

Figure 5. The CUL1-SKP1-FBXL20 complex mediates the ubiquitination of Vps34. $(A, B) 293$ T cells were transfected with the expression vectors of HA-Vps34, Flag-FBXL20, and His-Ub as indicated for $48 \mathrm{~h}$ and then treated with $25 \mu \mathrm{M} \mathrm{MG132}$ for $4 \mathrm{~h}$. The cell lysates were subjected to pull-down assay with Ni-NTA beads. The ubiquitination of exogenous or endogenous Vps34 was analyzed by Western blotting with the indicated antibodies. (C) 293T cells were transfected with an expression vector for Flag-ubiquitin and incubated for $24 \mathrm{~h}$, and then $2 \mu \mathrm{M}$ CPT was added and incubated for another $24 \mathrm{~h}$ before adding $10 \mu \mathrm{M}$ MG132 for $2 \mathrm{~h}$. The cell lysates were subjected to immunoprecipitation with anti-Vps34 antibody and analyzed by Western blotting using anti-Flag antibody. $(D)$ Flag-ubiquitin expression vector together with either control GFPshRNA vector or GFPshRNA vector targeting FBXL20 was transfected into HeLa cells and cultured for $48 \mathrm{~h}$, and then $2 \mu \mathrm{M}$ CPT was added. Twenty-four hours later, $10 \mu \mathrm{M}$ MG132 was added for an additional $2 \mathrm{~h}$. The cell lysates were subjected to immunoprecipitation with anti-Vps34 antibody and analyzed by Western blotting with the indicated antibodies. $(E)$ MycCullin1/SKP1, Flag-Vps34, and Flag-FBXL20 proteins were purified individually from 293T cells that were transfected with the indicated expression vectors. The eluted proteins were incubated with recombinant E1 and E2-Ubc5c in an in vitro ubiquitin ligation reaction. One part of the reaction mixture was analyzed by Western blotting using anti-Flag, anti-Myc, and anti-SKP1 antibodies. The rest of the mixture was incubated with HA-agarose. Ubiquitination of Vps34 was measured with anti-HA-Vps34 and anti-Ub antibodies.

mutant and FBXL20 was also stronger than that of Vps34 wild type (Fig. 6F; Supplemental Fig. S6A). On the other hand, mutations in T668, which is in the kinase domain, had no effect with its interaction with FBXL20. This result is consistent with the importance of the $\mathrm{C} 2$ domain in binding to FBXL20 and suggests that T159 is a negative factor in the binding of Vps34 with FBXL20.
To further characterize the functional role of T159 in CPT-mediated Vps34 degradation, we compared the stability of T159A and T159E mutants upon CPT treatment. Interestingly, the levels of T159A mutant protein were largely unaffected by CPT, whereas the levels of T159E mutant protein were still reduced upon CPT treatment (Fig. 6G; Supplemental Fig. S6B). Thus, although Vp34T159A 
Xiao et al.

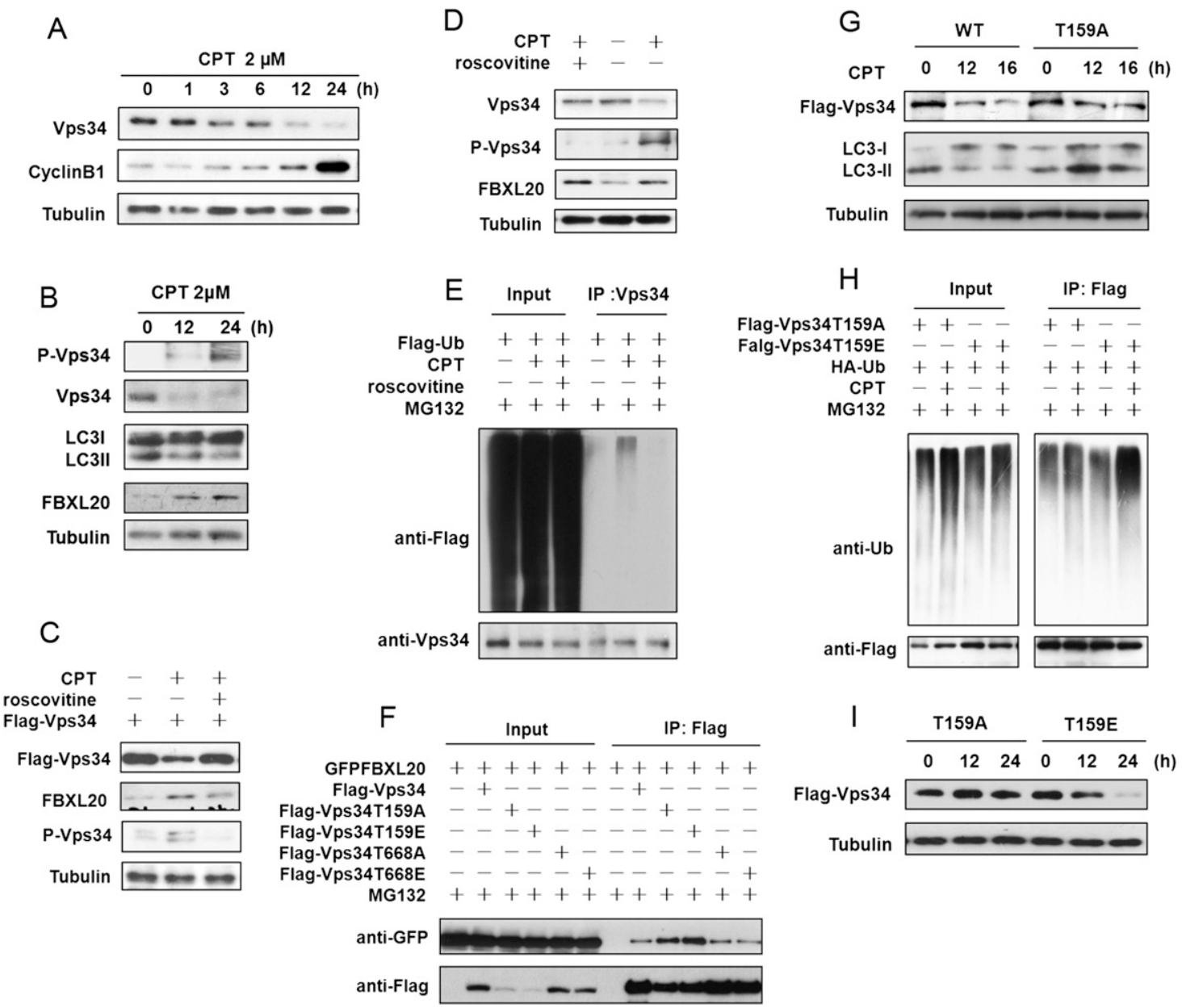

Figure 6. FBXL20-mediated degradation of Vps34 is regulated by CDK1-mediated T159 phosphorylation. $(A, B)$ HeLa cells were treated with $2 \mu \mathrm{M}$ CPT for the indicated durations, and the cell lysates were analyzed by Western blotting with the indicated antibodies. (p-Vps34) p-T159Vps34 ab. $(C, D) 293 \mathrm{~T}$ cells $(C)$ or HeLa cells $(D)$ were transfected with Flag-Vps34 expression vector, cultured for $24 \mathrm{~h}$ $(C)$, and treated with $2 \mu \mathrm{M}$ CPT in the presence or absence of $10 \mu \mathrm{M}$ roscovitine for an additional $24 \mathrm{~h}$. The cell lysates were analyzed by Western blotting with the indicated antibodies. (E) 293T cells were transfected with Flag-Ub for $24 \mathrm{~h}$ and then treated with $2 \mu \mathrm{M}$ $\mathrm{CPT}$ in the presence or absence of $10 \mu \mathrm{M}$ roscovitine. Twenty-four hours later, the cells were lysed in immunoprecipitation (IP) buffer. The cell lysates were subjected to immunoprecipitation with anti-Vps34 antibody, and the ubiquitination of Vps34 was analyzed by Western blotting with anti-Flag antibody. $(F)$ 293T cells were transfected with expression vectors of Flag-Vps34 wild type (WT) or Vps34 mutants with that of GFP-FBXL20 as indicated and cultured for $48 \mathrm{~h}$. The cell lysates were subjected to immunoprecipitation with anti-Flag antibody, and the immunocomplexes were analyzed by Western blotting with anti-GFP or anti-Flag antibody. $(G)$ T159A mutant maintains the levels of autophagy in CPT-treated cells. HeLa cells were transfected with expression vectors for wild-type or mutant Vps34 and cultured for $24 \mathrm{~h}$ and then treated with $2.5 \mu \mathrm{M}$ CPT for the indicated time. The cell lysates were analyzed by Western blotting with the indicated antibodies. $(H)$ The expression vectors for the indicated Flag-Vps34 mutants were transfected to $293 \mathrm{~T}$ cells and cultured for $48 \mathrm{~h}$. The cells were then treated with CPT for $22 \mathrm{~h}$ and MG132 for an additional $2 \mathrm{~h}$ before harvesting. The cell lysates were analyzed by immunoprecipitation using anti-Flag antibody, and the ubiquitination of Vps34 mutants was analyzed by Western blotting with the indicated antibodies. (I) $293 \mathrm{~T}$ cells were transfected with the indicated expression vectors of Vps34 mutants and treated with $2 \mu \mathrm{M}$ CPT for the indicated durations. The cells lysates were analyzed by Western blotting using the indicated antibodies.

can bind to FBXL20, it is not sufficient for promoting its degradation. We conclude that the phosphorylation of T159 is likely to be critical for CPT-induced ubiquitination and degradation of Vps34. Consistent with this possibility, the T159A mutant was largely resistant to CPT-induced ubiquitination (Fig. 6H). Thus, although the T159A mutant could bind to FBXL20 (Fig. 6F), it is deficient for ubiquitination induced by DNA damage. Interestingly, the expres- sion of the Vps34 T159A mutant was able to maintain the levels of autophagy in CPT-treated cells (Fig. 6G). On the other hand, T159E, a phosphor-mimetic mutant, remained sensitive to CPT-induced reduction of Vps34 and ubiquitination by FBXL20 (Fig. 6H,I). These results suggest that the phosphorylation of T159 is a key regulatory site for mediating the ubiquitination and degradation of $\mathrm{Vps} 34$ by FBXL20 upon DNA damage. 
p53 regulates receptor degradation through FBXL20regulated Vps34 degradation

Since the class III PtdIns3 kinase and its product, PtdIns3P, are critical in mediating endocytosis and receptor degradation (Herman and Emr 1990; Backer 2008), we reasoned that the ability of p53 to control the levels of FBXL20 and regulated Vps34 ubiquitination and degradation might provide a mechanism for p53 to regulate receptor degradation through controlling the activity of Vps34 complexes. We first assessed the impact of knocking down FBXL20 on FYVE-dsRed spots in H4 cells expressing FYVE-deRed, an assay for the levels of intracellular PtdIns(3)P (Stenmark et al. 2002; Zhang et al. 2007). We found that knockdown of FBXL20 significantly increased the levels of FYVE-deRed spots, consistent with the increased levels of Vps34 (Fig. 7A). On the other hand, the treatment with CPT, which increased the levels of FBXL20, led to reduced levels of FYVE-deRed spots, suggesting that DNA damage response leads to a reduction in the levels of PtdIns(3)P. The reduced levels of FYVE-deRed spots in cells treated with CPT can be restored by knocking down FBXL20 or p53, consistent with the roles of FBXL20 and p53 in negatively regulating the levels of PtdIns(3)P.

To further characterize the significance of p53- and FBXL20-regulated Vps34 activity, we next examined the impact of FBXL20 and p53 on the rate of cells to internalize and degrade epidermal growth factor receptor (EGFR) upon EGF stimulation, which is known to be regulated by Vps34 (Tomas et al. 2014). Upon binding of EGF with EGFR, the ligand-receptor complex is internalized through endocytosis and then transported by multivesicular vesicles to lysosomes, where the complexes are degraded (Lai et al. 1989). Compared with that of control knockdown cells, siRNA-mediated knockdown of FBXL20 led to significant increases in the levels of Vps34 and acceleration in the degradation of EGFR (Fig. 7B). In cells treated with CPT, which led to a reduction in the levels of Vps34, the rate of EGFR degradation was correspondingly reduced (Fig. 7C). On the other hand, knockdown of FBXL20 accelerated EGFR degradation upon DNA damage induced by CPT treatment (Fig. 7D).

To assess the impact of p53 in the degradation of EGFR, we compared the rate of EGF-stimulated EGFR degradation in HCT116 cells expressing control or shp53. We found that knocking down the expression of p53 in CPT-treated cells significantly accelerated the degradation of EGFR (Fig. 7E). We measured the levels of EGFR in HCT116 wild-type and HCT116 p53-null cells. Consistently, the degradation of EGFR upon EGF stimulation was also accelerated in HCT116 p53-null cells (Supplemental Fig. S7). Taken together, we conclude that control of FBXL20 expression by p53 provides a mechanism to regulate the rate of receptor degradation upon DNA damage.

\section{Discussion}

In this study, we describe FBXL20 as an adaptor protein for a SCF complex-regulated ubiquitination and proteasomal degradation of Vps34 upon the activation of DNA damage response. Activation of FBXL20 by a p53-con- trolled transcriptional mechanism leads to down-regulation of Vps34, which in turn inhibits autophagy and receptor degradation. Although p53 activation has been suggested to lead to enhancement in autophagy (Kenzelmann Broz et al. 2013), our study shows that the enhancement of autophagy upon the activation of a DNA damage response is only transient; prolonged activation of a DNA damage response leads to inhibition of autophagy. The early activation of autophagy upon DNA damage induced by chemotherapeutic agents is likely due to cellular responses to cell injury (Zhang et al. 2007). On the other hand, prolonged treatment with chemotherapeutic agents, which leads to mitotic arrest, may inhibit autophagy by CDK-mediated phosphorylation of Vps34 activated as a result of mitotic arrest. Since a chemotherapeutic regimen typically lasts much more than a few hours, the physiologically relevant response of activating p53 likely leads to suppression of autophagy.

On the mechanistic front, our study suggests that p53regulated FBXL20 expression may provide an important checkpoint for p53 to regulate autophagy. Furthermore, we show that the binding and ubiquitination of Vps34 by FBXL20 depends on phosphorylation of T159. Since phosphorylation of the recognition sequence in the substrates of SCF complexes, the degrons, is known to promote ubiquitination, we suggest that T159 may be a part of the degron for the recognition and ubiquitination of Vps34 by FBXL20. We show that the expression of FBXL20 is suppressed in p53 wild-type HCT116 cells and can be activated upon DNA damage. Transient knockdown of p53 expression leads to the loss of inducibility of FBXL20 upon DNA damage response. On the other hand, this p53-controlled FBXL20 expression is lost in p53 $3^{-1-}$ HCT116 cells, leading to its constant elevated expression, which might be due to the adaptation of tumor cells upon the loss of p53. The elevated expression of FBXL20 in p53 ${ }^{-/-}$HCT116 cells leads to reduced levels of Vps34 and autophagy.

Endocytosis plays a critical role in cancer development and treatment (Mellman and Yarden 2013). By mediating selective vesicular packaging of cell surface proteins, including receptors for growth factors, cytokines, and adhesion components, endocytosis regulates the levels of key cancer drivers by regulating their degradation in lysosomes or recycling back to the plasma membrane. Our study provides a previously unexpected link between a p53-mediated DNA damage response and receptor endocytosis/degradation. The ability of p53 to regulate the levels of class III PtdIns3 kinase suggests that p53 wildtype cancer cells may be able to down-regulate receptor endocytosis/degradation upon DNA damage through transcriptionally up-regulated FBXL20 to promote the degradation of Vps34. On the other hand, in p53-null cancer cells, this transcriptional checkpoint is lost, which leads to the inability of DNA damage to regulate endocytosis and autophagy.

FBXL20 has been identified as a key target for miR3151 , which is associated with poor outcomes in cytogenetically normal acute myeloid leukemia (CN-AML) patients (Eisfeld et al. 2012). miR-3151is encoded in intron 1 of the $B A A L C$ (the brain and acute leukemia 
A

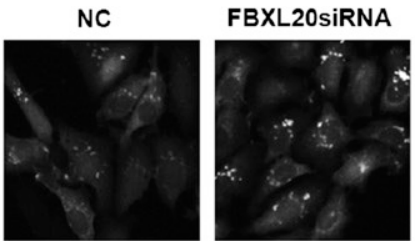

$N C+C P T$
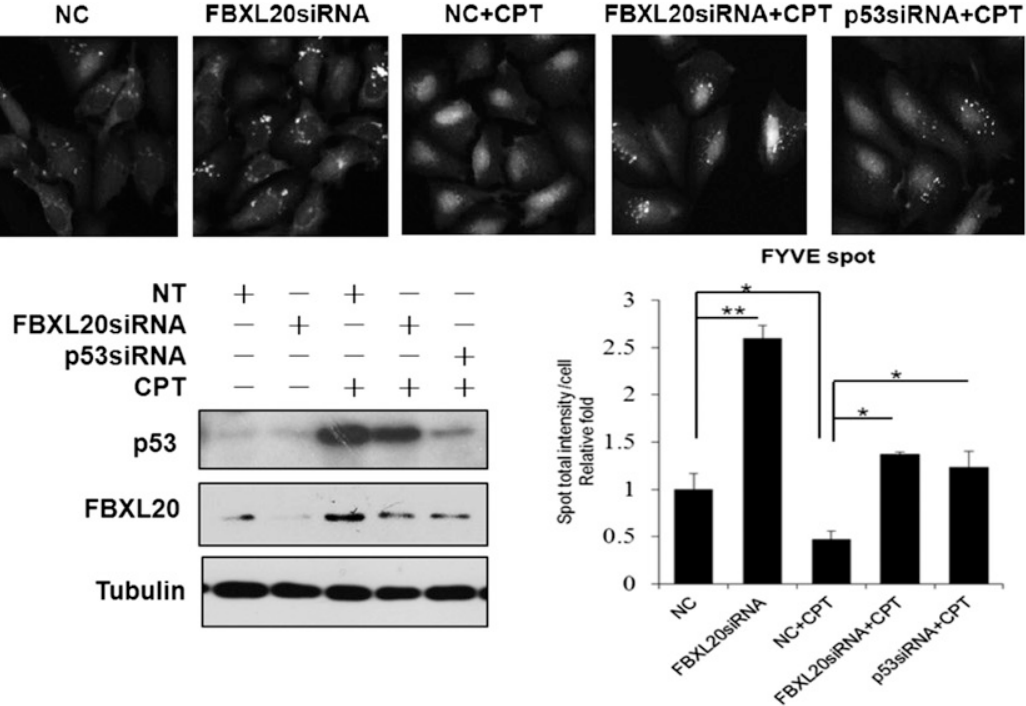

B
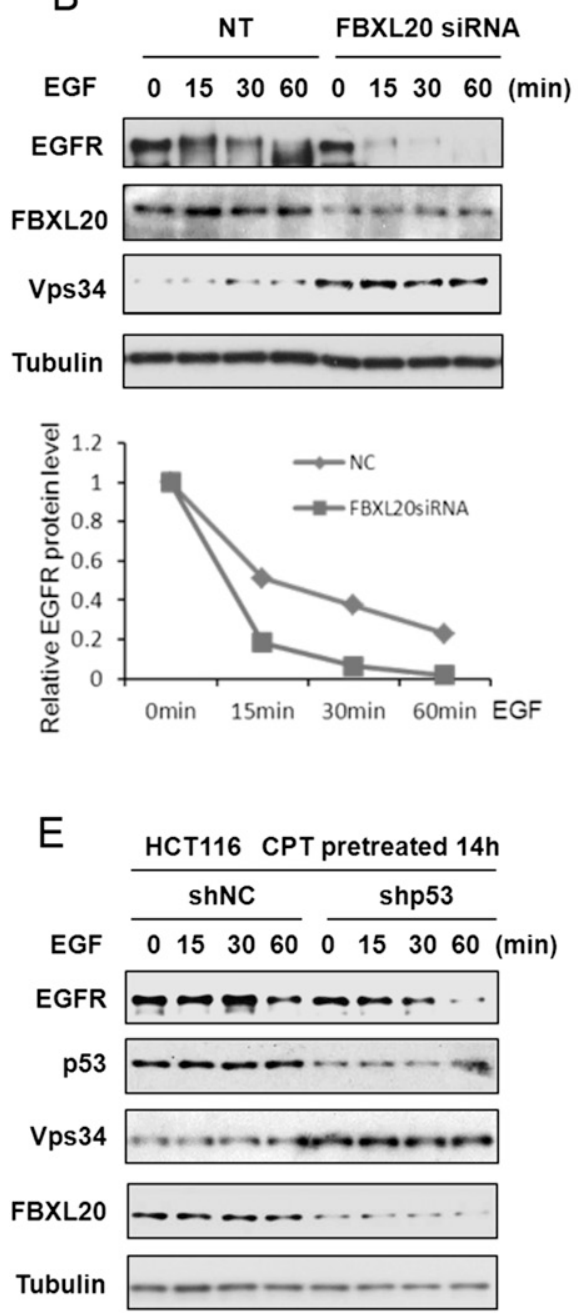

C
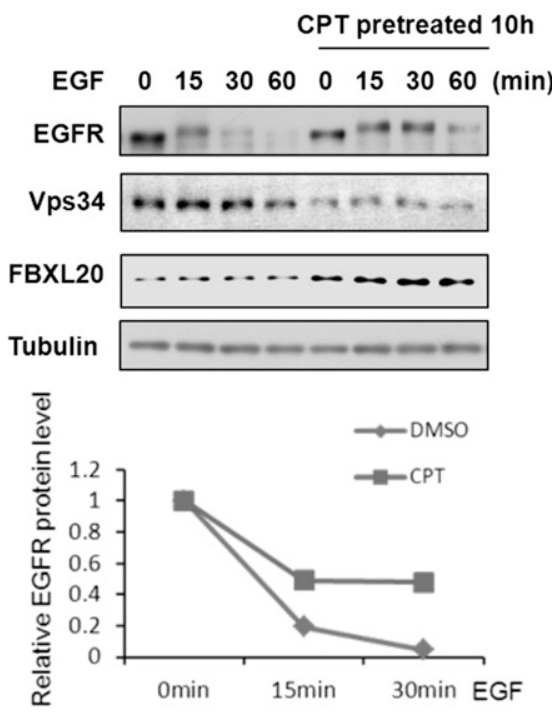

D

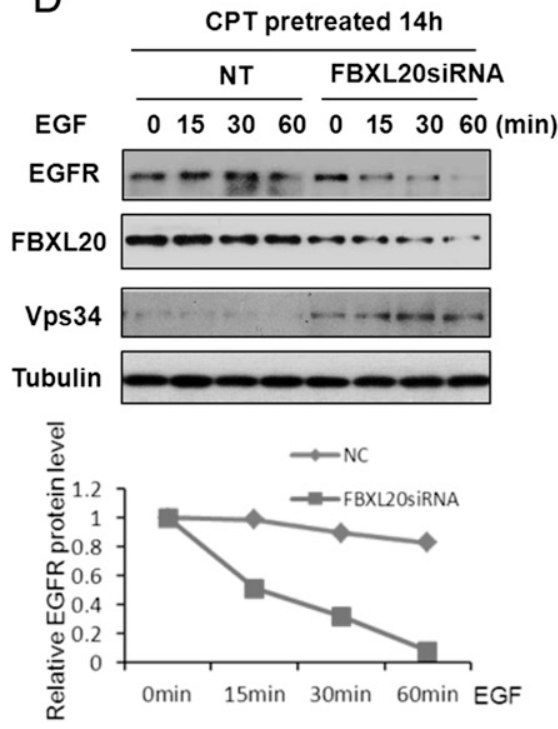

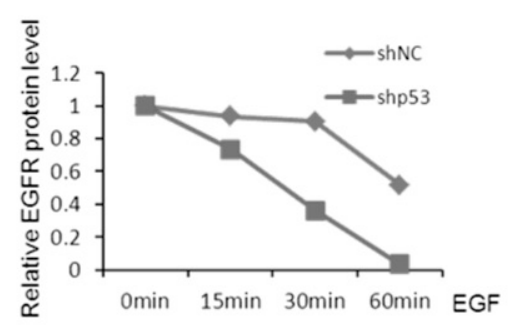

Figure 7. Regulation of receptor degradation by FBXL20 and p53. (A) H4-FYVE-deRed cells were transfected with control siRNA or siRNA targeting FBXL20 or p53 for $48 \mathrm{~h}$ and then treated with or without CPT for $14 \mathrm{~h}$. The cells were fixed with $4 \%$ PFA and stained with $3 \mu \mathrm{g} / \mathrm{mL}$ DAPI. The image data were collected with an ArrayScan HCS 4.0 reader. RNAi efficiency was checked by Western blotting with the indicated antibodies. $\left(^{\star \star}\right) P<0.01 ;\left(^{\star}\right) P<0.05$. $(B, D)$ HeLa cells were transfected with control siRNA or siRNA targeting FBXL20; $48 \mathrm{~h}$ later, the cells were treated with or without CPT for $14 \mathrm{~h}$ and then deprived of serum for $2 \mathrm{~h}$, during which $100 \mathrm{ng} / \mathrm{mL}$ EGF was added for the indicated durations. The cell lysates were analyzed by Western blot with anti-EGFR, anti-FBXL20, or anti-Vps34 antibodies. $(C)$ HeLa cells were treated with or without CPT for $10 \mathrm{~h}$, and then cells were cultured in serum-free medium for $2 \mathrm{~h}$, during which $100 \mathrm{ng} / \mathrm{mL}$ EGF was added for the indicated durations. The cell lysates were analyzed by Western blot with the indicated antibodies. $(E)$ HCT116 wild-type (wt) cells were transfected with control shRNA or shRNA targeting p53; $48 \mathrm{~h}$ later, cells were treated with or without CPT for $14 \mathrm{~h}$ and then deprived of serum for $2 \mathrm{~h}$, during which $100 \mathrm{ng} / \mathrm{mL}$ EGF was added for the indicated durations. The cell lysates were analyzed by Western blot with the indicated antibodies. The graphs were quantified using ImageJ from two independent sets of experiments. 
cytoplasmic) gene, an important contributor of negative clinical outcomes for CN-AML. High miR-3151 expression was associated with shorter disease-free and overall survival. FBXL20 was validated as a direct miR-3151 target and was negatively regulated by miR-3151. Our results suggest that decreased expression of FBXL20 in CN-AML cells may lead to increased levels of Vps34 and autophagy, which in turn support the survival of cancer cells under stress (Bellodi et al. 2009).

FBXL20 is localized in the presynaptic terminals in the CNS and targets a set of presynaptic proteins for degradation by the ubiquitin-proteasome system (Yao et al. 2007). SCR(FBXL20 $)^{-1-}$ mice displayed enhanced neurotransmission with an increased frequency of miniature excitatory postsynaptic currents. Our study demonstrates the possibility that knockdown of FBXL20 could lead to the up-regulation of Vps34 alone without corresponding changes in the levels of other components, such as Beclin1, Vps34, and Atg14L; the loss of FBXL20 in SCR(FBXL20) ${ }^{-1-}$ mice might disrupt this tightly coregulated complex and lead to the presence of excess Vps34 without the company of Beclin1, Vps34, and Atg14L, etc. Given the role of Vps34 in regulating membrane trafficking, it is possible that regulation of Vps34 ubiquitination and degradation contributes to the effect of $\mathrm{SCR}^{-1-}$ mice (Takagi et al. 2012) and therefore is involved in the regulation of synaptic activity and neurotransmission. Since endocytosis has been shown to regulate synaptic quantal size and strength, in turn generating synaptic plasticity, maintaining exocytosis, and clearing release sites for vesicle replenishment ( $\mathrm{Wu}$ et al. 2014), the control of Vps34 levels by FBXL20-CUL1-SKP1-mediated ubiquitination and proteasomal degradation may provide an important regulatory mechanism for endocytic control of synaptic transmission.

\section{Materials and methods}

\section{Chemicals and antibodies}

The following commercial antibodies were used: rabbit antiVps34 (PTG), rabbit anti-FBXL20 (Abcam), goat anti-FBXL20 (Santa Cruz Biotechnology), rabbit anti-p53 (PTG), rabbit antiLC3 (Sigma), mouse anti-Beclin1 (Santa Cruz Biotechnology), rabbit anti-Atg14 (MBL), rabbit anti-GFP (Santa Cruz Biotechnology), mouse anti-GFP (Abmart), mouse anti-HA (Abmart), rabbit anti-Atg12-Atg5 (Epitomics), rabbit anti-CUL1 (Epitomics), rabbit anti-Skp1 (Epitomics), mouse anti-Flag (Sigma), mouse anti-Myc (Sigma), rabbit anti-ubiquitin (Dako), and rabbit anti-Tubulin (MBL). Chemicals were from Sigma.

\section{Cell lines and culture conditions}

293T, HeLa, and human neuroglioma H4 cells were cultured in DMEM supplemented with $10 \%$ normal calf serum, $1 \%$ penicillin-streptomycin (GIBCO-BRL), and $1 \%$ sodium pyruvate. H4GFP-LC3, HCT116, and HCT116 p53-/- cells were cultured in DMEM with $10 \%$ FBS and $1 \%$ penicillin-streptomycin. siRNA or plasmid transient transfections were performed with Hiperfect transfect reagent or Polyjet transfect reagent according to the manufacturers' instructions. GFPshRNA stable cell lines were established using selection with $1 \mathrm{mg} / \mathrm{mL}$ G418 (Invitrogen).
Plasmids

GFP-FBXL20, Flag-FBXL20, and Flag-FBXL20_Fbox vectors were gifts from Dr. Mitsutoshi Setou (Fujita Health University).

\section{Western blotting and immunoprecipitation}

For Western blotting, cells were lysed in NP40 buffer $150 \mathrm{mM}$ Tris- $\mathrm{HCl}$ at $\mathrm{pH} 7.5,150 \mathrm{mM} \mathrm{NaCl}, 1 \mathrm{mM}$ cocktail, $50 \mathrm{mM} \mathrm{NaF}, 1$ $\mathrm{mM} \mathrm{Na}_{3} \mathrm{VO}_{4}, 0.5 \%$ NP-40) supplemented with a complete protease inhibitor cocktail (Roche), and the supernatant (cell lysates) was collected after centrifugation. The lysates were resolved by SDS-polyacrylamide gel electrophoresis (PAGE) and transferred to a PVDF membrane (Millipore). After probing with the indicated primary antibodies and then anti-rabbit or anti-mouse IgG secondary antibodies (Southern Biotech), the reactions were visualized by chemiluminescence regents. Immunoprecipitation was performed using NP40 buffer with a complete protease inhibitor mix. Primary antibodies were added and incubated overnight at $4^{\circ} \mathrm{C}$. The protein G-agarose beads were added to the mixture and incubated for $2 \mathrm{~h}$ at $4^{\circ} \mathrm{C}$. After three washings, the immunoprecipitation products were directly boiled in sample buffer.

\section{Quantitative fluorescent microscopy after FBXL20 RNAi}

H4-LC3-GFP cells were grown in 12-well plates. Seventy-two hours after FBXL20 RNAi, cells were fixed for $20 \mathrm{~min}$ in $4 \%$ paraformaldehyde/PBS and stained with $3 \mathrm{mg} / \mathrm{mL}$ DAPI (Sigma). Image data were collected with an ArrayScan HCS 4.0 reader with a 203 objective (Cellomics ArrayScan VTI) for DAPI-labeled nuclei and GFP-tagged intracellular proteins.

\section{Cell imaging and statistical analysis}

Cells were fixed with $4 \%$ paraformaldehyde (Sigma) and stained with $3 \mu \mathrm{g} / \mathrm{mL}$ DAPI (Sigma). Image data were collected with an ArrayScan HCS 4.0 reader with a 203 objective /Cellomics ArrayScan VTI) for DAPI-labeled nuclei and GFP/RFP-tagged intracellular proteins. Error bars for microscopy are presented as the standard deviation of triplicate samples. Error bars for Western blot analysis represent the standard deviation between densitometry data from three independent experiments. Student's $t$-test was used for statistical analysis using GraphPad Prism.

\section{His-Ub pull-down assay}

A His-Ub vector with other indicated expression vectors was transfected into $293 \mathrm{~T}$ cells for $48 \mathrm{~h}$, and then lysis buffer $(8 \mathrm{M}$ urea, $100 \mathrm{mM} \mathrm{NaH} \mathrm{PO}_{4}, 10 \mathrm{mM}$ Tris- $\mathrm{HCl}$ at $\mathrm{pH} 8.0,500 \mathrm{mM}$ $\mathrm{NaCl}, 10 \%$ glycerol, $0.1 \%$ Triton X-100, $10 \mathrm{mM} \beta$-mercaptoethanol, $10 \mathrm{mM}$ imidazole) was added. Cell lysates were boiled and incubated with Ni-NTA agarose beads for $4 \mathrm{~h}$ at room temperature with rotating. The beads were washed with washing buffer (lysis buffer $+20 \mathrm{mM}$ imidazole) and eluted with elution buffer $(0.15 \mathrm{M}$ Tris- $\mathrm{HCl}$ at $\mathrm{pH} 6.7,5 \%$ SDS, 30\% glycerol, 200 $\mathrm{mM}$ imidazole, $0.72 \mathrm{M} \beta$-mercaptoethanol). The eluted proteins were analyzed by Western blotting.

\section{In vitro ubiquitination assay}

Myc-Cullin1/SKP1/Myc-ROC1, Flag-Vps34, and Flag-FBXL20 proteins were immunopurified from $293 \mathrm{~T}$ cells transfected with the indicated expression vectors individually. The eluted proteins were incubated with $60 \mathrm{ng}$ of recombinant E1, $300 \mathrm{ng}$ of E2Ubc5c, and $1 \mu \mathrm{g}$ of ubiquitin in an in vitro ubiquitin ligation reaction (final volume, $30 \mu \mathrm{L}$ ) containing $50 \mathrm{mM}$ Tris- $\mathrm{HCl}(\mathrm{pH}$ 7.4), $5 \mathrm{mM} \mathrm{MgCl}_{2}, 10 \mathrm{nM}$ okadaic acid, $2 \mathrm{mM}$ ATP, $0.6 \mathrm{mM}$ DTT, 
and $1 \mu \mathrm{g}$ of ubiquitin. The reactions were incubated for $60 \mathrm{~min}$ at $37^{\circ} \mathrm{C}$ and terminated by boiling for $5 \mathrm{~min}$ in SDS sample buffer.

\section{Acknowledgments}

We thank Dr. Mitsutoshi Setou and his team for the kind gifts of expression constructs of FBXL20 and FBXL20 $\Delta$-Fbox. This work was supported in part by grants (to J.Y.) from the Chinese Academy of Sciences, the National Institute on Aging (NIA) (R37 AG012859 and 1R01AG047231), and the National Institute of Neurological Disorders and Stroke (NINDS) (1R01NS082257); a Senior Fellowship from the Ellison Foundation; and a grant from the Global Research Laboratory Program (GRL) (NRF-2010-00341) by the Ministry of Science and Technology (MEST) in Korea.

\section{References}

Backer JM. 2008. The regulation and function of class III PI3Ks: novel roles for Vps34. Biochem J 410: 1-17.

Bellodi C, Lidonnici MR, Hamilton A, Helgason GV, Soliera AR, Ronchetti M, Galavotti S, Young KW, Selmi T, Yacobi R, et al. 2009. Targeting autophagy potentiates tyrosine kinase inhibitor-induced cell death in Philadelphia chromosomepositive cells, including primary CML stem cells. I Clin Invest 119: 1109-1123.

Cardozo T, Pagano M. 2004. The SCF ubiquitin ligase: insights into a molecular machine. Nat Rev Mol Cell Biol 5: 739-751.

Carrano AC, Eytan E, Hershko A, Pagano M. 1999. SKP2 is required for ubiquitin-mediated degradation of the CDK inhibitor p27. Nat Cell Biol 1: 193-199.

Cheng G, Kong D, Hou X, Liang B, He M, Liang N, Ma S, Liu X. 2013. The tumor suppressor, p53, contributes to radiosensitivity of lung cancer cells by regulating autophagy and apoptosis. Cancer Biother Radiopharm 28: 153-159.

Eisfeld AK, Marcucci G, Maharry K, Schwind S, Radmacher MD, Nicolet D, Becker H, Mrozek K, Whitman SP, Metzeler $\mathrm{KH}$, et al. 2012. miR-3151 interplays with its host gene BAALC and independently affects outcome of patients with cytogenetically normal acute myeloid leukemia. Blood 120: 249-258.

Funderburk SF, Wang QJ, Yue Z. 2010. The Beclin 1-VPS34 complex-at the crossroads of autophagy and beyond. Trends Cell Biol 20: 355-362.

Furuya N, Yu J, Byfield M, Pattingre S, Levine B. 2005. The evolutionarily conserved domain of Beclin 1 is required for Vps34 binding, autophagy and tumor suppressor function. Autophagy 1: 46-52.

Furuya T, Kim M, Lipinski M, Li J, Kim D, Lu T, Shen Y, Rameh L, Yankner B, Tsai LH, et al. 2010. Negative regulation of Vps34 by Cdk mediated phosphorylation. Mol Cell 38: 500-511.

Herman PK, Emr SD. 1990. Characterization of VPS34, a gene required for vacuolar protein sorting and vacuole segregation in Saccharomyces cerevisiae. Mol Cell Biol 10: 6742-6754.

Hupalowska A, Miaczynska M. 2012. The new faces of endocytosis in signaling. Traffic 13: 9-18.

Kenzelmann Broz D, Spano Mello S, Bieging KT, Jiang D, Dusek RL, Brady CA, Sidow A, Attardi LD. 2013. Global genomic profiling reveals an extensive p53-regulated autophagy program contributing to key p53 responses. Genes Dev 27: 1016-1031.

Lai WH, Cameron PH, Wada I, Doherty JJ 2nd, Kay DG, Posner BI, Bergeron JJ. 1989. Ligand-mediated internalization, recycling, and downregulation of the epidermal growth factor receptor in vivo. J Cell Biol 109: 2741-2749.

Levine B, Kroemer G. 2008. Autophagy in the pathogenesis of disease. Cell 132: 27-42.
Liang C, Feng P, Ku B, Dotan I, Canaani D, Oh BH, Jung JU. 2006. Autophagic and tumour suppressor activity of a novel Beclin1-binding protein UVRAG. Nat Cell Biol 8: 688-699.

Lipinski MM, Hoffman G, Ng A, Zhou W, Py BF, Hsu E, Liu X, Eisenberg J, Liu J, Blenis J, et al. 2010. A genome-wide siRNA screen reveals multiple mTORC1 independent signaling pathways regulating autophagy under normal nutritional conditions. Dev Cell 18: 1041-1052.

Mellman I, Yarden Y. 2013. Endocytosis and cancer. Cold Spring Harb Perspect Biol 5: a016949.

Mizushima N. 2011. Autophagy in protein and organelle turnover. Cold Spring Harb Symp Quant Biol 76: 397-402.

Simonsen A, Tooze SA. 2009. Coordination of membrane events during autophagy by multiple class III PI3-kinase complexes. J Cell Biol 186: 773-782.

Skaar JR, Pagan JK, Pagano M. 2013. Mechanisms and function of substrate recruitment by F-box proteins. Nat Rev Mol Cell Biol 14: 369-381.

Stenmark H, Aasland R, Driscoll PC. 2002. The phosphatidylinositol 3-phosphate-binding FYVE finger. FEBS Lett 513: 7784.

Takagi H, Setou M, Ito S, Yao I. 2012. SCRAPPER regulates the thresholds of long-term potentiation/depression, the bidirectional synaptic plasticity in hippocampal CA3-CA1 synapses. Neural Plast 2012: 352829.

Tomas A, Futter CE, Eden ER. 2014. EGF receptor trafficking: consequences for signaling and cancer. Trends Cell Biol 24: 26-34.

Wu LG, Hamid E, Shin W, Chiang HC. 2014. Exocytosis and endocytosis: modes, function, and coupling mechanisms. Annu Rev Physiol 76: 301-331.

Yao I, Takagi H, Ageta H, Kahyo T, Sato S, Hatanaka K, Fukuda Y, Chiba T, Morone N, Yuasa S, et al. 2007. SCRAPPERdependent ubiquitination of active zone protein RIM1 regulates synaptic vesicle release. Cell 130: 943-957.

Zhang L, Yu J, Pan H, Hu P, Hao Y, Cai W, Zhu H, Yu AD, Xie X, $\mathrm{Ma} D$, et al. 2007. Small molecule regulators of autophagy identified by an image-based high-throughput screen. Proc Natl Acad Sci 104: 19023-19028. 


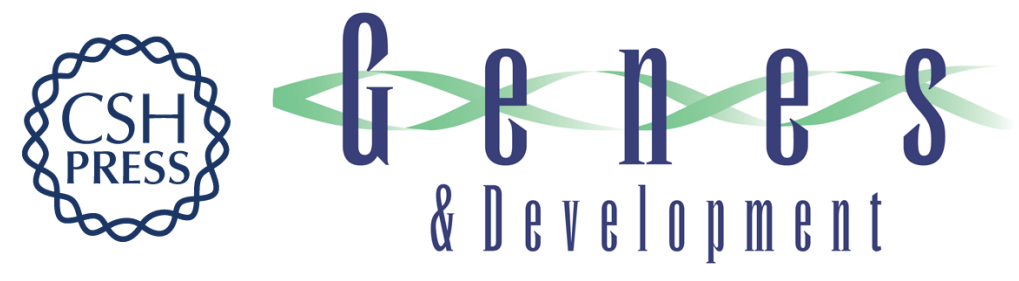

\title{
FBXL20-mediated Vps34 ubiquitination as a p53 controlled checkpoint in regulating autophagy and receptor degradation
}

\author{
Juan Xiao, Tao Zhang, Daichao Xu, et al.
}

Genes Dev. 2015, 29:

Access the most recent version at doi:10.1101/gad.252528.114

\section{Supplemental http://genesdev.cshlp.org/content/suppl/2015/01/15/29.2.184.DC1 Material}

References This article cites 26 articles, 9 of which can be accessed free at: http://genesdev.cshlp.org/content/29/2/184.full.html\#ref-list-1

Creative This article is distributed exclusively by Cold Spring Harbor Laboratory Press for the first Commons six months after the full-issue publication date (see

License http://genesdev.cshlp.org/site/misc/terms.xhtml). After six months, it is available under a Creative Commons License (Attribution-NonCommercial 4.0 International), as described at http://creativecommons.org/licenses/by-nc/4.0/.

Email Alerting Receive free email alerts when new articles cite this article - sign up in the box at the top Service right corner of the article or click here.

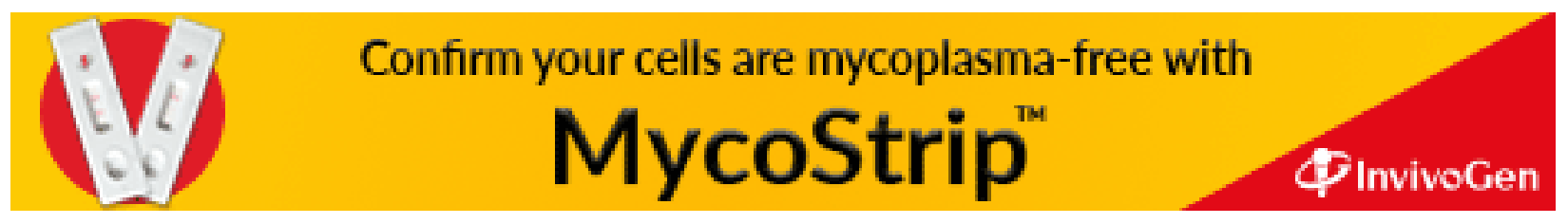

